\title{
Calculating the Contact Stress Resulting from Lateral Movement of the Wheel on Rail by Applying Hertz Theory
}

\author{
Roya Sadat Ashofteh ${ }^{\dagger}$
}

\begin{abstract}
This article has tried to review the maximum contact stresses in the contact area of the wheel and rail as a result of lateral movement of the wheel on rail by taking advantage from Hertz theory. Since wheel movement on rail is accompanied by lateral movement due to wheel profile conisity, so the contact point of wheel and rail is not constant and the contact stresses are therefore changeable in every single moment. Since the shape of rail profile and rail inclination, wheel diameter and the mechanical properties of the wheel and rail are effective on the stresses of contact area, these parameters have been studied by applying Hertz theory. This article aims to calculate the contact stresses in different parts on the wheel surface by using Hertz theory.
\end{abstract}

Keywords : Railway, Wheel, Rail, Contact stress, Hertz theory

\section{Introduction}

Wheel set is the most important component among the different components of a car and this component plays a very important role in safety and also economic issues for the railway industry. From safety point of view, wheel profile should be able to ensure the consistent movement of car movement, and from economic point of view, this issue should be kept in mind that a lot of financial sources are spent annually to replace or turn a wheel in the railway transportation system. The trend towards increasing the speed of trains on rail tracks and the increase of axle load has resulted in higher wheel-rail contact forces. Such forces are the main causes of wheel damages including wear and fatigue.

\section{Wheel/Rail Profiles and the Theory Governing the Contact Area}

Wheel is the means of movement and guiding the car on rail. Wheel diameter in typical railway vehicles is between

\footnotetext{
Corresponding author: Raja Rail transportation Co.

E-mail : roya_ashofteh@yahoo.co.uk

(c) The Korean Society for Railway 2013

http://dx.doi.org/10.7782/IJR.2013.6.4.148
}

850 to $1000 \mathrm{~mm}$ which is increased if the axle load is increased. Since the bogie axles are of solid type, and on the other hand, the width of the track is a bit more than the outer distance between two flanges of the wheel $(1426 \mathrm{~mm})$, there will be a gap between the wheel flange and side of the rail (1426-1435=9). Thus, forward movement of the bogie can be accompanied by the lateral movement of axle with the value of $9 \mathrm{~mm}$. Type of wheel profile in Iran is consistent with UIC regulations, S1002 (Fig. 1).

Based on the variety of the capacity of passenger and load transportation (number of compartments and the lay out of the train), their wheel diameters are also different.

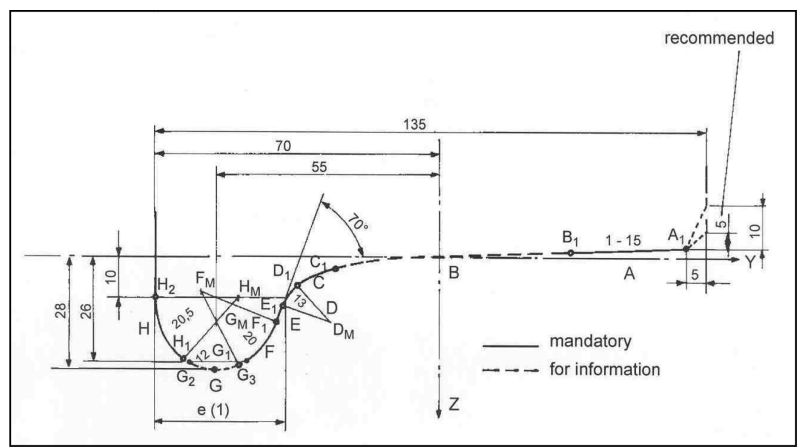

Fig. 1 Wheel profile of type UIC S1002 [1] 


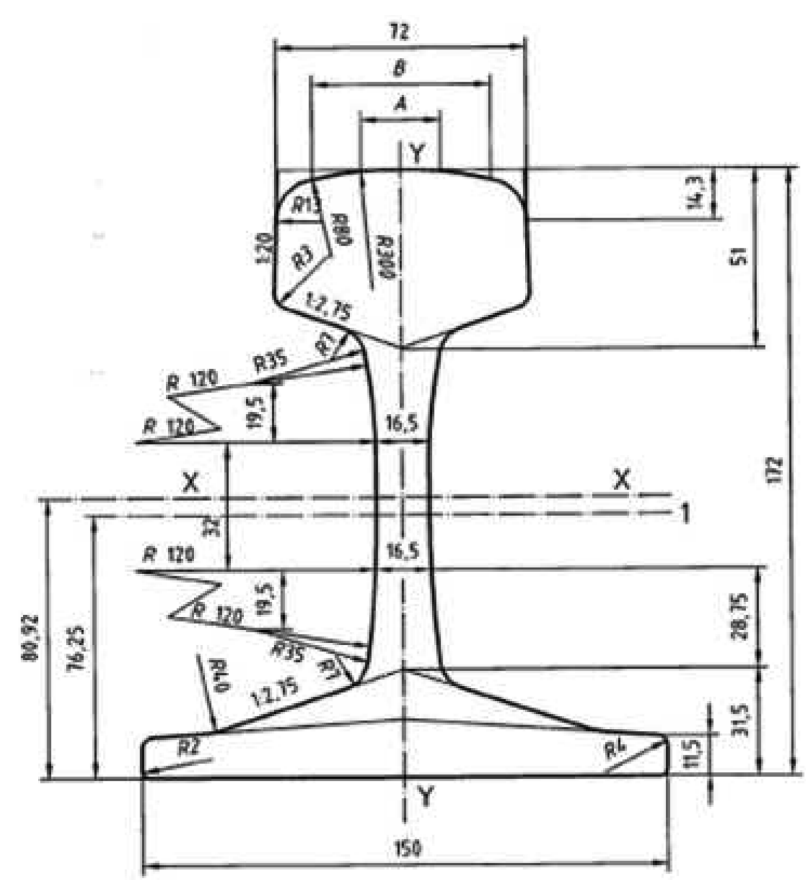

Fig. 2 rail profile UIC 60 [2]

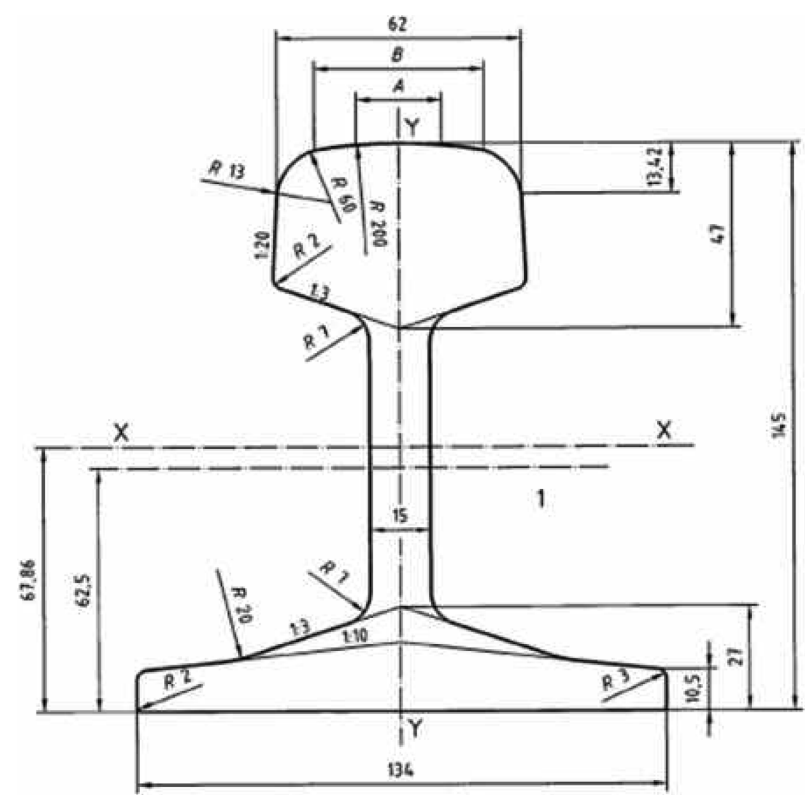

Fig. 3 rail profile U33 [2]

Existing solid wheels in Iran are R7T. Rail is responsible for bearing the weight of the wheels of the vehicle and guiding them. The profile of most of the Iranian rails is of UIC60 type (Fig. 2) and U33 (Fig. 3).

The theory governing the wheel/rail contact is Hertz theory. This theory describes this fact that when two solid materials are compressed to each other by vertical loads,
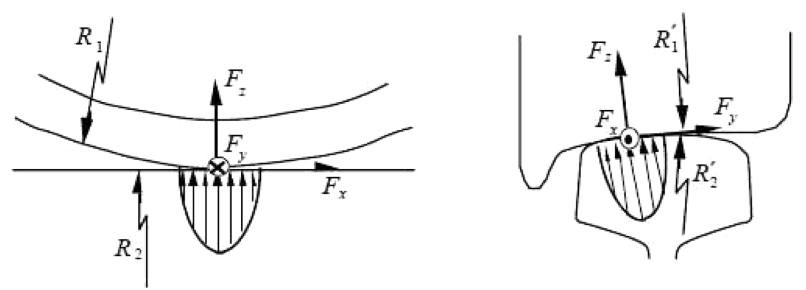

Fig. 4 major curves of the wheel and rail- $F_{z}$ vertical force and $F_{x}$ and $\mathrm{F}_{\mathrm{y}}$ are the contact forces in contact with wheel and rail [3]

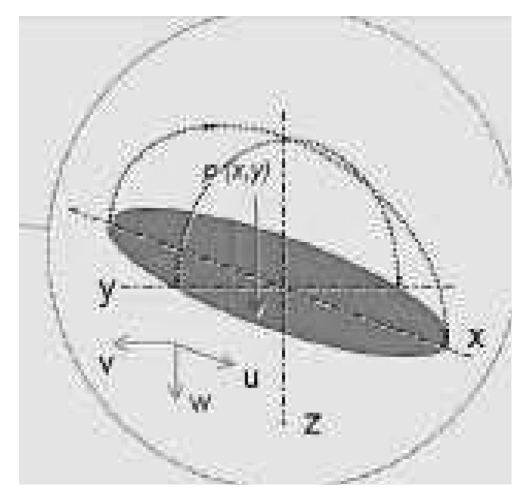

Fig. 5 elliptical of the contact area between wheel and rail [4]

their contact area is formed. Shape and the value of the contact area between two elastic materials are at static mode.

$\mathrm{R}_{1}$ is considered as the major rolling radius of the wheel, $\mathrm{R}_{2}$ as the major rolling radius of the rail (which is normally infinite in rails), $R_{1}^{\prime}$ as the lateral curve radius of the width of the wheel profile at the contact area and $R_{2}^{\prime}$ is the lateral curve radius of rail profile curve. Since the radius of wheel and rail is different from each other, the contact area will be ellipse as a result (Fig. 5).

To calculate the elliptical contact area using Hertz theory, the following equations are applied [5]:

$$
\begin{aligned}
& 2(A+B)=\frac{1}{R_{1}^{\prime}}+\frac{1}{R_{1}}+\frac{1}{R_{2}}+\frac{1}{R_{2}^{\prime}} \\
& 2(B-A)= \\
& \sqrt{\left(\frac{1}{R_{1}}-\frac{1}{R_{1}^{\prime}}\right)^{2}+\left(\frac{1}{R_{2}}-\frac{1}{R_{2}^{\prime}}\right)^{2}+2\left(\frac{1}{R_{1}}-\frac{1}{R_{1}^{\prime}}\right)\left(\frac{1}{R_{2}}-\frac{1}{R_{2}^{\prime}}\right) \operatorname{Cos} 180}
\end{aligned}
$$

After solving the above mentioned equation, parameters $\mathrm{A}$ and $\mathrm{B}$ are achieved. By having the ration of $\mathrm{A} / \mathrm{B}$ in hand, it is possible to use Matlab and calculate $\varphi 1$ and $\varphi 2$ according to equation number 2 by giving 1 to 10 values to $\mathrm{k}$ ( $\mathrm{k}$ is the ration of the bigger radius of the contact area (a) to the radius of the smaller radius of the contact area (b)). Where the ration of $\mathrm{A} / \mathrm{B}$ and $\varphi 1 / \varphi 2$ is close to each 
other, $\mathrm{k}$ will be acceptable.

$$
\begin{gathered}
\phi_{1}=\int_{0}^{\infty} \frac{d \xi}{\sqrt{\xi(1+\xi)^{3}\left(\frac{1}{k^{2}}+\xi\right)}} \\
\phi_{2}=\int_{0}^{\infty} \frac{d \xi}{\sqrt{\xi(1+\xi)\left(\frac{1}{k^{2}}+\xi\right)^{3}}}
\end{gathered}
$$

By having the vertical load (F), and to calculate a (elliptical radius of the contact area), equation number 3 is applied:

$$
A+B=\frac{3}{4}\left(\delta_{1}+\delta_{2}\right) \frac{F}{a^{3}}\left(\phi_{1}+\phi_{2}\right)
$$

$\delta 1$ and $\delta 2$ are the parameters related to the material of the components(equations no 4).

$$
\begin{gathered}
\delta_{1}=\frac{1-v_{1}^{2}}{\pi E_{1}} \\
\delta_{2}=\frac{1-v_{2}^{2}}{\pi E_{2}}
\end{gathered}
$$

b can also be calculated by using the following formula.

$$
k=\frac{a}{b}
$$

Ave. pressure (stress) in the contact area is also achieved by the following equation:

$$
P=\frac{3 F}{2 \pi a b}
$$

Hertz theory is considered based on material behavior in the contact area, at static mode and ignoring friction coefficient.

\section{Calculating the Contact Tensions in the Contact Area of the Wheel and Rail Applying Hertz Theory}

Based on Hertz theory claiming that contact area in front of the curve radius of two objects should be minimal, this theory is not applicable whenever there is a wheel flange and rail rim contact. Thus, Hertz theory only applies the contact area of the tread and the area above the rail. To calculate the contact stresses in the contact area of wheel and rail, geometrical parameters of wheel and rail (major and lateral curve radius), mechanical properties of wheel and rail (elasticity module and Poisson coefficient) should be clarified. In software modeling, in static mode of the wheel is considered contact point of the wheel and rail is at $70 \mathrm{~mm}$ with regard to wheel rim and wheel weight is applied on wheels in this point. Because of wheel profile conisity of wheel profile, wheel movement on rail is accompanied by lateral displacement. So, contact stresses are variable at any given time. Contact stresses in different points on wheel surface are calculated based on Hertz theory. Wheel curve equation at rolling area is as the following [1]:

$$
\begin{aligned}
Z= & \frac{3.358537058}{100} Y+\frac{1.565681624}{1000} Y^{2}-\frac{2.810427944}{100000} Y^{3} \\
& +\frac{5.844240864}{10^{8}} Y^{4}-\frac{1.562379023}{10^{8}} Y^{5}+\frac{5.309217349}{10^{15}} Y^{6} \\
- & \frac{5.957839843}{10^{12}} Y^{7}+\frac{2.646656573}{10^{13}} Y^{8}
\end{aligned}
$$

Thus, wheel curve in the point contact with rail is calculated as the following:

$$
k=\frac{\left|Z^{\prime \prime}\right|}{\left(1+Z^{\prime 2}\right)^{\frac{3}{2}}}
$$

Wheel curve radius considering $70 \mathrm{~mm}$ from the wheel rim is achieved at $\mathrm{Y}=0$ (Cartesian mathematic $\mathrm{Y}-\mathrm{Z}$ system in Fig. 1).

$$
R_{1}^{\prime}=\frac{1}{k}=\frac{\left(1+1.127977 \times 10^{-3}\right)^{\frac{3}{2}}}{3.13 \times 10^{-3}} \approx 320 \mathrm{~mm}
$$

3.1 calculation of maximum pressure stress for passenger wheel (Fig. 6) and UIC60 rail

Total weight of passenger cars with this type of passenger wheel is almost 51 tons (loaded with passengers).

As a result, applied force on each wheel is almost $63.750 \mathrm{kN}$. The material of this passenger wheel is R7T steel. Based on the major and lateral curve radius of wheel and rail,

$$
R_{1}=460 \mathrm{~mm}, R_{1}^{\prime}=-320 \mathrm{~mm}, R_{2}=300 \mathrm{~mm}, R_{2}^{\prime}=\infty .
$$

Wheel specifications: $E=206000 \mathrm{MPa}, v=0.27$ and rail with $E=210000 M P a, v=0.3, \delta 1$ and $\delta 2$ are achieved:

$$
\begin{aligned}
& \delta_{1}=\frac{1-v^{2}}{\pi E}=\frac{1-(0.27)^{2}}{\pi(206000)}=1.4325 \times 10^{-6} \\
& \delta_{2}=\frac{1-v^{2}}{\pi E}=\frac{1-(0.3)^{2}}{\pi(210000)}=1.379 \times 10^{-6}
\end{aligned}
$$

Based on equations in 1 , we will have the following 


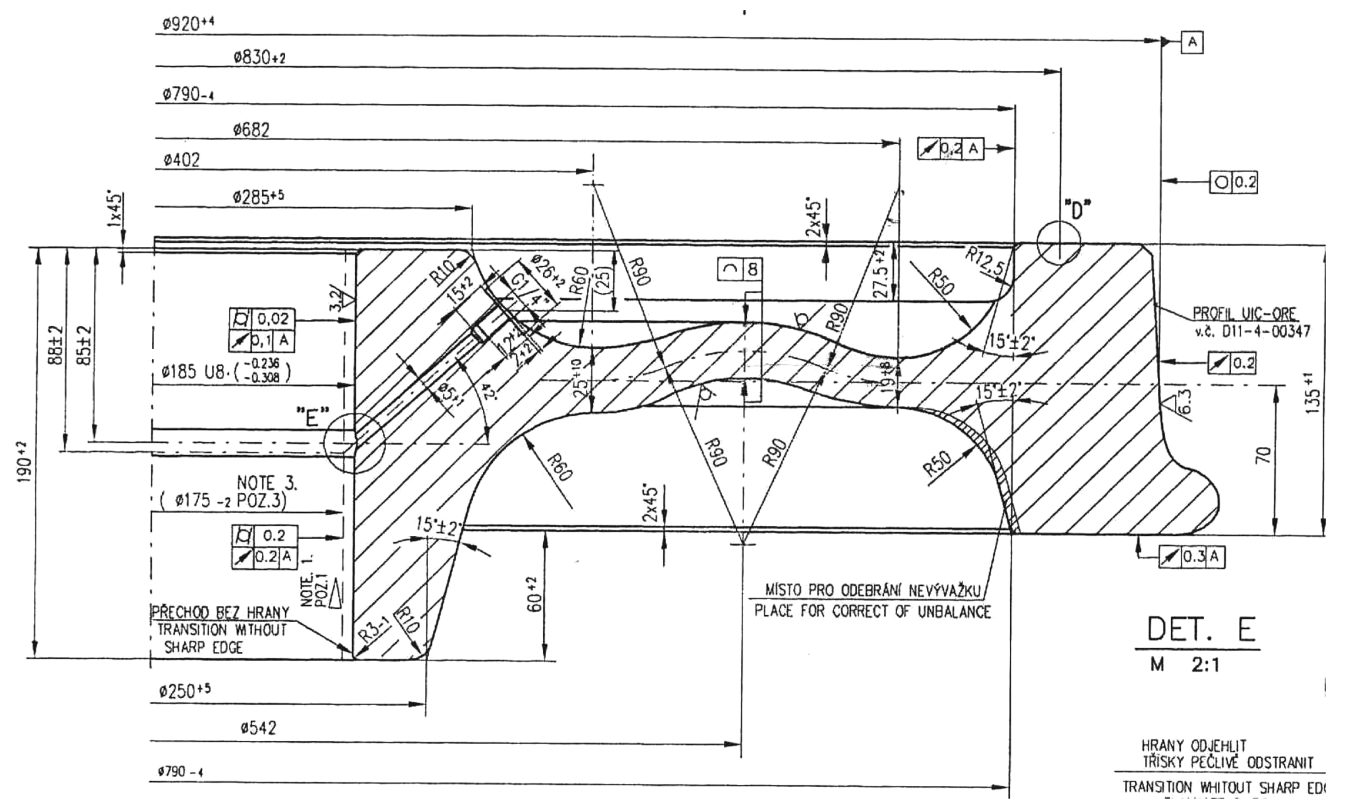

Fig. 6 Iran wheel drawing with the diameter of $920 \mathrm{~mm}$

result:

$$
\begin{aligned}
& 2(A+B)=\frac{1}{460}+\frac{1}{300}+\frac{-1}{320}=2.3822 \times 10^{-3} \\
& 2(B-A)=\sqrt{\left(\frac{1}{460}+\frac{1}{320}\right)^{2}+\left(\frac{1}{300}\right)^{2}+2\left(\frac{1}{460}+\frac{1}{320}\right)\left(\frac{1}{300}\right) \cos 180} \\
& =1.9656 \times 10^{-3} \\
& \Rightarrow A=1.0414 \times 10^{-4}, B=1.0869 \times 10^{-3}, \frac{A}{B}=0.0958
\end{aligned}
$$

Thus, based on the reply on programming respecting A/ $\mathrm{B}$ ratio, the radii of Hertz elliptical diameter in the contact area of wheel and rail, maximum pressure stress can be calculated as the following:

$$
\begin{aligned}
& \frac{A}{B}=0.0958 \rightarrow k=\frac{a}{b}=4.625 \rightarrow \phi_{1}=3.94993, \phi_{2}=41.37497 \\
& (A+B)=\frac{3}{4}\left(\delta_{1}+\delta_{2}\right) \frac{F}{a^{3}}\left(\varphi_{1}+\varphi_{2}\right) \rightarrow \\
& 1.191 \times 10^{-3}=\frac{3}{4}\left(2.8115 \times 10^{-6}\right) \frac{6.375 \times 10000}{a^{3}}(45.3249) \\
& \rightarrow a=17 . \mathrm{mm} \\
& b=3.6 \mathrm{~mm} \\
& p_{0}=\frac{3}{2} \frac{F}{\pi a b}=\frac{3}{2} \frac{6.375 \times 1000}{\pi(17 .)(3.6)}=497 \mathrm{MPa}
\end{aligned}
$$

\subsection{The same passenger wheel in contact with U33 rail}

In this case:

$$
R_{1}=460 \mathrm{~mm}, R_{1}^{\prime}=-320 \mathrm{~mm}, R_{2}=200 \mathrm{~mm}, R_{2}^{\prime}=\infty \text {. }
$$

Thus, Ave. pressure at the contact area will be as the following:

$$
P_{0}=\frac{3}{2} \frac{F}{\pi a b}=\frac{3}{2} \frac{63750}{\pi(6.2)(5.6)} \approx 876 M P a
$$

based on the achieved stresses and comparing stress values with the yield stress of the wheel steel which is almost between 473-543 $\mathrm{MPa}$ [6], it can be understood if the wheel steel with the rail will enter the plastic limit in the contact area or not.

Results in items 3.1 and 3.2 show that the contact stress between R7T wheel and U33 rail is more than the contact at R7T wheel and UIC60 rail.

\section{Calculating Maximum Pressure Stress at the Contact Area of Wheel and Rail Based on Lateral Movement of Contact Point}

Base on Hertz theory and Matlab software, the value of maximum pressure stress can be calculated for all types of wheels with different diameters (as software input) and also different types of rails based on curve radius in the contact area with wheel and based on steel material of 
Table 1 Maximum pressure stress based on the movement of contact point of passenger wheel and UIC60 rail

\begin{tabular}{cc}
\hline \hline $\mathrm{Y}(\mathrm{mm})$ & $\mathrm{P}(\mathrm{MPa})$ \\
\hline 0 & 497 \\
\hline 2 & 601.2 \\
\hline 4 & 688.0 \\
\hline 6 & 762.5 \\
\hline$\ldots$ & $\ldots$ \\
\hline 10 & 902.7 \\
\hline 20 & 1278.6 \\
\hline 25 & 1442.4 \\
\hline 30 & 1489.3 \\
\hline 31 & 1469.6 \\
\hline 32 & 1434.4 \\
\hline
\end{tabular}

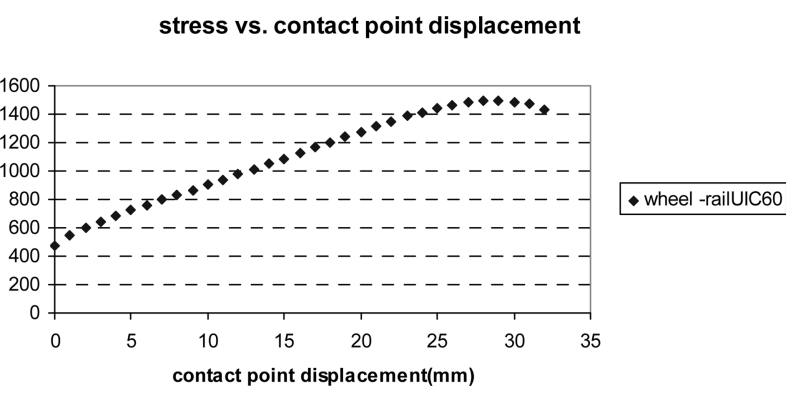

Fig. 7 Graph of maximum pressure stress based on the movement of contact point of passenger wheel and UIC60 rail

Table 2 Maximum pressure stress based on movement of contact point of passenger wheel and U33 rail

\begin{tabular}{cc}
\hline $\mathrm{Y}(\mathrm{mm})$ & $\mathrm{P}(\mathrm{MPa})$ \\
\hline 0 & 876 \\
\hline 2 & 912.2 \\
\hline 4 & 958.14 \\
\hline 6 & 1004.19 \\
\hline$\ldots$ & $\ldots$ \\
\hline 10 & 1103.37 \\
\hline 20 & 1414.5 \\
\hline 25 & 1561.18 \\
\hline 30 & 1603.84 \\
\hline 31 & 1585.9 \\
\hline 32 & 1553.9
\end{tabular}

wheel and rail. The following results are for passenger wheels (Fig. 6) and UIC60 rail.

For passenger wheel (Fig. 6) and U33 rail, the results are

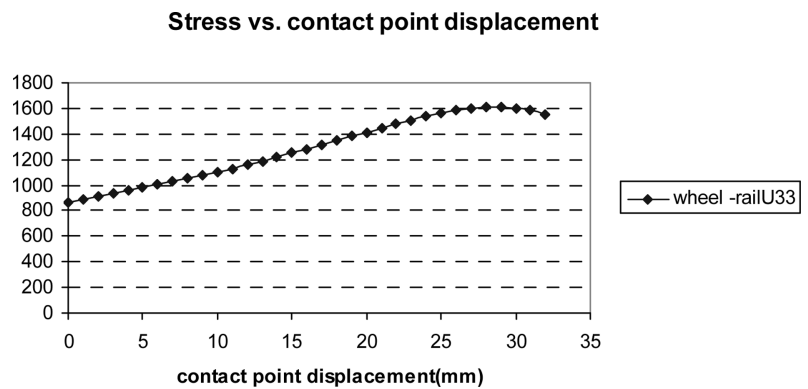

Fig. 8 graph of maximum pressure stress based on movement of contact point of passenger wheel and U33 rail

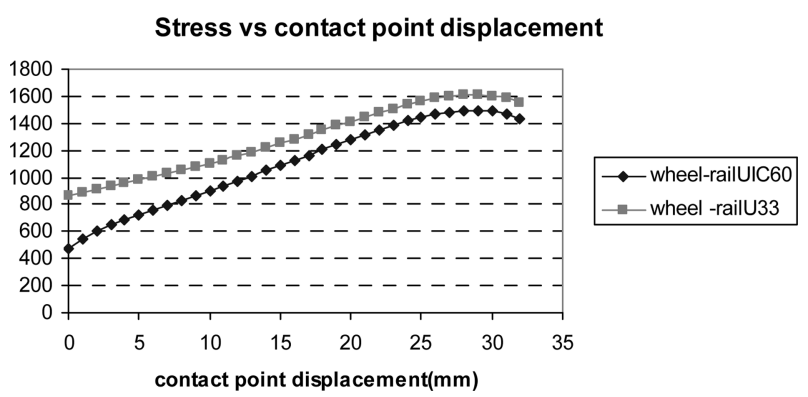

Fig. 9 graph to compare movement of contact point based on maximum pressure stress for both rails

Table 3 Half of the contact elliptical based on the movement of contact point of passenger wheel and $\mathrm{U} 33$ rail

\begin{tabular}{ccc}
\hline \hline $\mathrm{Y}(\mathrm{mm})$ & $\mathrm{a}(\mathrm{mm})$ & $\mathrm{b}(\mathrm{mm})$ \\
\hline 0 & 6.2 & 5.6 \\
\hline 2 & 5.8 & 5.7 \\
\hline 4 & 5.94 & 5.34 \\
\hline 6 & 6.07 & 4.98 \\
\hline$\ldots$ & $\ldots$ & $\ldots$ \\
\hline 10 & 6.32 & 4.36 \\
\hline 20 & 6.92 & 3.107 \\
\hline 25 & 7.13 & 2.73 \\
\hline 30 & 7.19 & 2.63 \\
\hline 31 & 7.17 & 2.67 \\
\hline 32 & 7.12 & 2.74
\end{tabular}

as the Table 2 .

Table 3 shows the geometrical dimensions of the contact area elliptical.

Figs. 10 and 11 show Hertz ellipse based on the movement of the contact point between wheel and rail contact from 0 to $32 \mathrm{~mm}$ for UIC60 and U33 rails. Horizontal axis is based on the movement of contact point of wheel and rail based on bigger diameter of the ellipse (2a) and vertical axis is based on smaller axis of the ellipse (2b). 


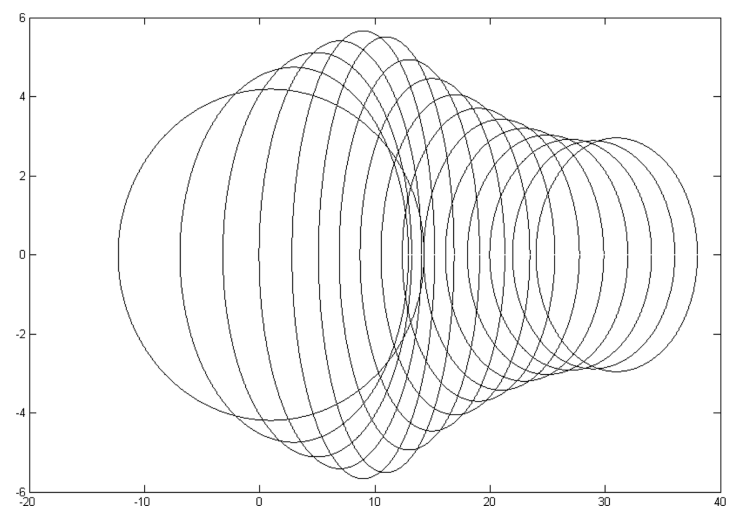

Fig. 10 Graph of Hertz ellipse based on the movement of contact point of wheel and UIC60 rail

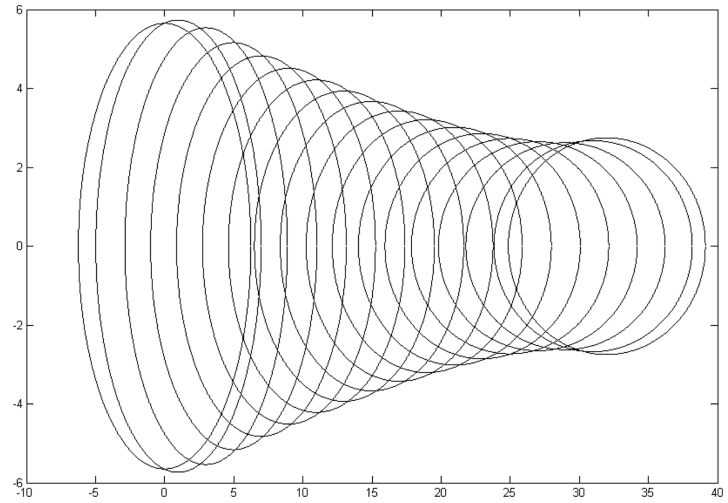

Fig. 11 Graph of Hertz ellipse based on the movement of contact point of wheel and $\mathrm{U} 33$ rail

Table 4 Wheel displacement based on the movement of contact point of passenger wheel and UIC60

\begin{tabular}{cc}
\hline \hline $\begin{array}{c}\text { Wheel displacement on rail } \\
(\mathrm{mm})\end{array}$ & $\begin{array}{c}\text { Contact point of wheel and rail } \\
(\mathrm{mm})\end{array}$ \\
\hline$\ldots$ & $\ldots$ \\
\hline-9 & Im. \\
\hline-8 & -19.1 \\
\hline-1 & -1.06 \\
\hline 0 & 0 \\
\hline 1 & 0.95 \\
\hline 3 & 2.66 \\
\hline 5 & 4.16 \\
\hline 7 & 5.6 \\
\hline$\ldots$ & $\ldots$ \\
\hline 10 & 7.5 \\
\hline 20 & 13.4 \\
\hline 30 & 18.9 \\
\hline 31 & 19.5 \\
\hline 32 & 20.1 \\
\hline
\end{tabular}

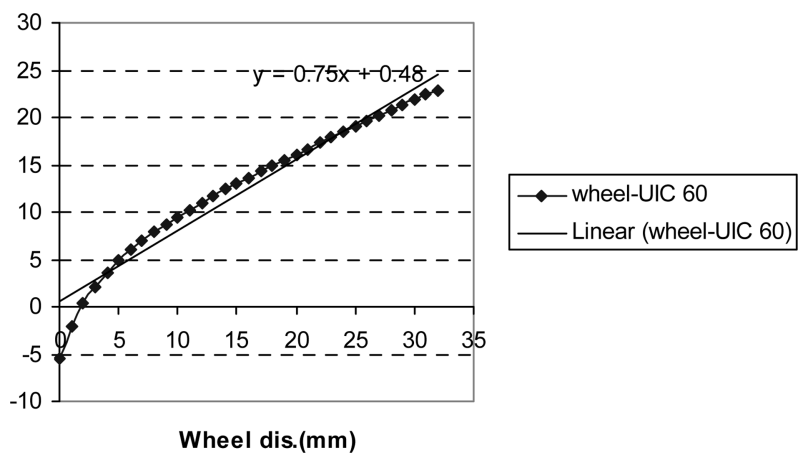

Fig. 12 Wheel displacement based on the displacement of contact point of wheel in contact with UIC60 rail

Table 5. Wheel displacement based on the displacement of contact point between the passenger wheel and U33 rail

\begin{tabular}{cc}
\hline \hline $\begin{array}{c}\text { Wheel displacement on rail } \\
(\mathrm{mm})\end{array}$ & $\begin{array}{c}\text { Contact point of wheel and rail } \\
(\mathrm{mm})\end{array}$ \\
\hline$\ldots$ & $\ldots$ \\
\hline-5 & Im. \\
\hline-4 & -7.85 \\
\hline-1 & -1.08 \\
\hline 0 & 0 \\
\hline 1 & 0.935 \\
\hline 3 & 2.53 \\
\hline 5 & 3.915 \\
\hline 7 & 5.171 \\
\hline$\ldots$ & $\ldots$ \\
\hline 10 & 6.912 \\
\hline 20 & 12.19 \\
\hline 30 & 17.26 \\
\hline 31 & 17.77 \\
\hline 32 & 18.28 \\
\hline
\end{tabular}

Based on the fact that, wheel has a hunting process during rolling movement on rail which is because of wheel profile conisity, and based on the fact that wheel curve in the rolling area with rail curve is of order 8[1], the contact point of wheel and rail will be different by displacement of wheel. Based on the software of Matlab, contact point of wheel and rail will be calculated for displacement of $1 \mathrm{~mm}$ of the wheel on rail from a distance of $-26 \mathrm{~mm}$ to $+32 \mathrm{~mm}$ of contact point of wheel and rail based on the following table:

By paying attention to the Fig. 12, it is clear that their relationship is not of linear type and what really exists is the wheel displacement.

The interesting point is that there is no kind of contact 


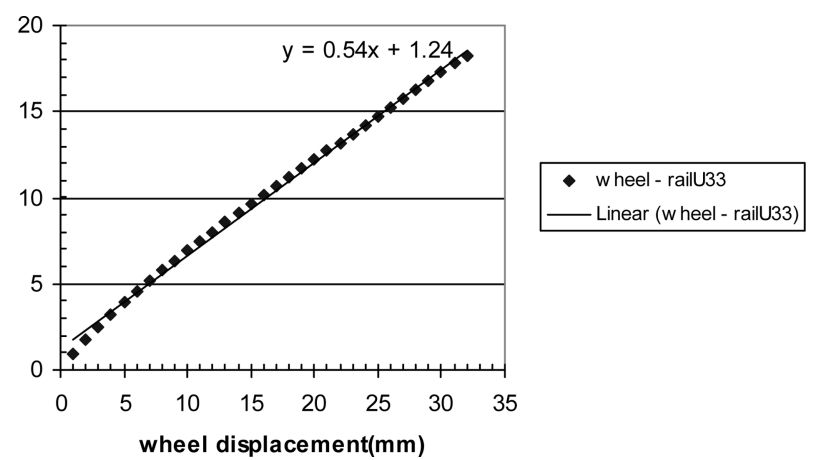

Fig. 13 Wheel displacement based on the displacement of contact point and wheel in contact with $\mathrm{U} 33$ rail

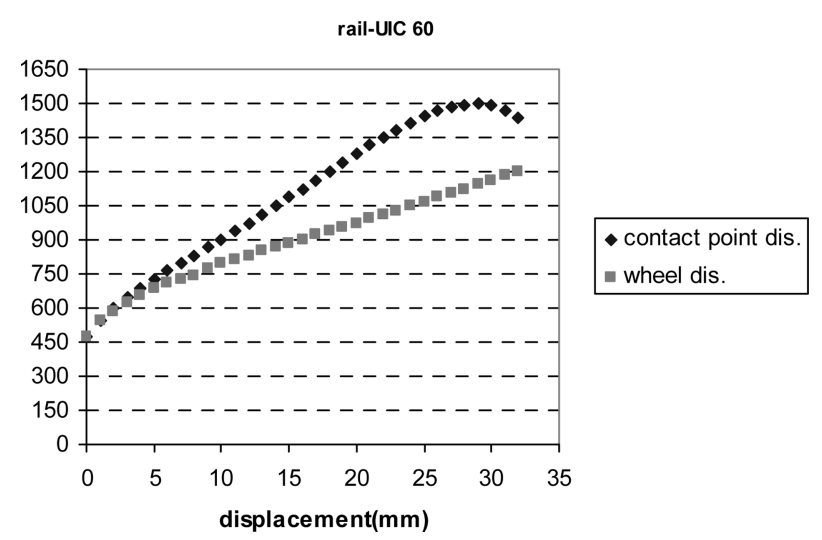

Fig. 14 Comparison of pressure maximum pressure stresses for the displacement of wheel and the displacement of contact point-rail UIC60

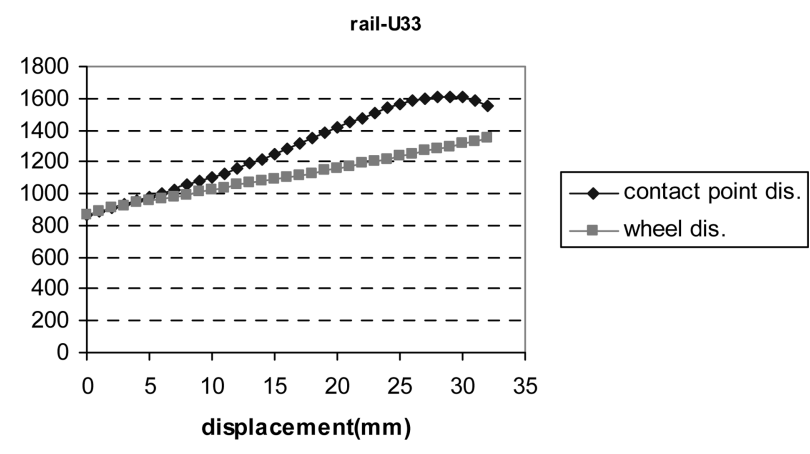

Fig. 15 Comparison of maximum pressure stresses for the displacement of wheel and the displacement of contact point-rail U33

point between the wheel and rail for a movement of wheel for $-9 \mathrm{~mm}$ with respect to UIC60 rail and $-5 \mathrm{~mm}$ of wheel respecting U33 rail. This is itself a factor for the re-jumping of the wheel on rail so that it can keep its balance on rail based on conisity. This kind of return movement will continue again.

Following figures show a comparison between maximum pressure stresses for passenger wheel with UIC60 rail and U33 rail based on wheel and contact point displacement.

\section{Conclusion}

Transversal wheel movement on rails would produce tensions 3 times in intensity. The rolling movement of wheel that is more harmonious and with lesser a transversal displacement on the rails would render to lesser contact tension. A maximum pressure stress is created due to an approximately $30 \mathrm{~mm}(3 \mathrm{~cm})$ of wheel displacement on rail. The pressure stress during wheel and U33 rail tribology is higher than the same kind of contact between a wheel and UIC60 rail.

Axle load, straight track or a curved one, geometrical of wheel and rail profile, wheel diameter, rail and wheel material, rail curve radius in contact point with wheel are effective factors at wheel life so that increasing stresses at contact area, decreasing the wheel life. However some parameters cannot be calculated but also are affected on wheel life as the followings:

Thermal treatment, surface hardening, heat and temperature (due to exceeding braking), anti-skid system-cars equipped with brake shoe, wheel situation (guiding or nonguiding axles), suspension system...

\section{References}

1. UIC 510-2 OR, "Trailing Stock: Wheel and Wheel Sets Conditions Concerning the use of Wheels of Various Diameters", 4th edition, 2004.

2. EN 13674-1 (2003). "Railway Applications-Track-Rail", Part 1: Vignole railway rails $46 \mathrm{~kg} / \mathrm{m}$ and above.

3. Ekberg, A. (2003). "Rolling Contact Fatigue of railway wheels-computer Modeling and In-field Data", Chalmers University of technology, Sweden.

4. Esveld, C. (2006). "Optimization of a Railway Wheel Profile", Delft University of technology.

5. Johnson, K.L. "Contact Mechanics", University of Cambridge.

6. Tunna, J., Sinclair, J. and Perez, J. (2007). "A Review of Wheel Wear and Rolling Contact Fatigue". 